\title{
Performance Criteria for Power-System Compatibility
}

\author{
François D. Martzloff \\ National Institute of Standards and Technology * \\ Gaithersburg, MD 20899
}

\begin{abstract}
Power electronics create an opportunity for better utilization of electric energy but can become a source of problems if the electromagnetic characteristics (immunity and emissions limits) of the equipment are not compatible with the characteristics (avoidable and unavoidable disturbances) of the power supply. Well-defined equipment performance criteria can help end-users obtain better compatibility, reliability, and cost effectiveness of the equipment - power supply combination.
\end{abstract}

\section{INTRODUCTION}

The ever-expanding application of power-electronics loads, the increasing dependency upon information processing systems, and the explosive development of power-system disturbance monitors (cum graphics) have produced a new level of concern about the compatibility of load equipment and power supply. Power-electronics loads are accused of polluting power delivery because of their nonlinear characteristics and the utilities are accused of delivering poor power quality. Meanwhile, the rapidly growing number of users of power-system disturbance monitors proudly display pictures of their 'glitch of the month' (in the way senior engineers used to pull pictures of their grandchildren out of their wallets) all to lament how bad the situation has become. It is time to take a fresh look at the situation and stop pointing fingers; instead, available resources should be applied to obtain better compatibility between hardware and software. Better compatibility is also needed among the three partners irrevocably involved, for better or for worse, in the power-electronics arena: the equipment suppliers, the electric power suppliers, and the end-users.

A new term has emerged and gained popularity in recent years: Power Quality. The basic need for satisfactory operation of equipment is well perceived by all. However, depending upon the point of view of those using this term, the interpretation of the term and the approach in achieving its objective are different. A clear definition, accepted by all interested parties, has yet to be developed.

* Electricity Division, National Institute of Standards and Technology, U.S. Department of Commerce, Technology Administration.
It may be useful to look back and benefit from the experience gained, long ago, in honing the concepts of electromagnetic compatibility because the quest for power quality proceeds along the same path as the broader topic of electromagnetic compatibility.

The performance of electrical equipment can often be described in fairly simple terms. Therefore, the subject of ratings, dimensions, and tolerances is readily addressed by the product standards developed by the manufacturers or by the purchasers, working jointly or separately. However, performance of equipment can be adversely impacted by electromagnetic disturbances and, conversely, the operation of equipment can emit disturbances that impact other equipment. Thus, avoiding electromagnetic interference (EMI) became an important field of engineering, but all too often it became a process of correcting problems rather than anticipating and preventing them. A more successful approach, both from the point of view of sound engineering practice and from the connotations of semantics, was the development of the concept of Electromagnetic Compatibility (EMC). One way to look at power quality issues would be to consider them as an interesting, dedicated subset of EMC, limited to the area of low-frequency conducted phenomena, as opposed to the 'dc-to-daylight' domain of the IEEE/EMC Society. An invitation for presenting a paper at this forum is an opportunity to complement the usual power quality dialogue, limited to end-users and electric utilities, by a three-way discussion that will include original equipment manufacturers (OEMs).

\section{THE NEED FOR STANDARDS}

Mass production of electrical and electronic equipment for the world market requires standards of world-wide applicability. Such standards are reference documents that provide solutions to technical or commercial problems in the transactions between contracting parties concerning products, goods or services. Standards act as a foundation to any contract.

U.S. Government work not protected by U.S. copyright. 
The development and implementation of power-quality standards is presently incompletely coordinated, in spite of all the efforts to provide coordination and liaison between the various standards-writing bodies. As an example, the European Directives on EMC take the position that electricity is a product, therefore subject to product standards of quality [1]. However, the conditions for optimum compatibility between the needs of equipment and the inherent characteristics of a power supply are not yet defined.

Product standards have reached a state of development where equipment survival in the field is adequately addressed, but the more subtle immunity to unavoidable disturbances is not addressed, to wit blinking clocks or industrial processes that shut down because their control systems lack sufficient ride-through capability during momentary power interruptions. Conversely, efforts to limit emissions of disturbances into the power system caused by normal operation of the equipment have faced a difficult challenge of achieving consensus, nationally as well as internationally [2], [3].

\section{Power Quality Surveys and Electromagnetic Environment Characterization}

From a handful of surveys of transient disturbances in the sixties and seventies, we now witness a multitude of large scale monitoring programs aimed at defining the power quality of the energy being delivered to endusers. An unresolved issue at this point is the translation (transformation) of objective measurements of electrical disturbances into a subjective statement of 'good power quality' or 'poor power quality' - the statement that typical decision-makers desire, but that engineers have difficulty in defining.

The term Power Quality has now gained too wide an acceptance to be changed, but it fails to convey the concept of reciprocity between the parties. A debate at a recent meeting of the IEEE Standards Coordinating Committee on Power Quality pointed out that a more accurate description of the Committee's scope would be Power Compatibility - but the committee resolved, with regrets, to go along with the entrenched usage. The IEEE attempts addressing these concerns with the steady development of voluntary Guides, Recommended Practices, and Standards. However, the process of consensus standards is all too often very slow, and sometimes delivers only broad (generic) rather than specific documents because of the lowest common denominator effect inherent in the consensus process.

Several national or international documents have been developed to classify the characteristics and disturbances of power systems. For instance, the normal steady-state conditions in U.S. power systems are defined in ANSI C84.1-1989 [4]; surges are described in ANSI/IEEE C62.41-1991 [5]; and an IEEE Guide is under development to describe the range of disturbances [6]. On the international scene, the variations in steady-state conditions and the types of transient disturbances are addressed by the Technical Committee 77 (TC77) on Electromagnetic Compatibility of the International Electrotechnical Commission. Table 1, excerpted from documents under consideration by the TC77 shows the list of these phenomena that cause radiated as well as conducted disturbances [7].

TABLE I

PRINCIPAL PHENOMENA CAUSING ELECTROMAGNETIC DISTURBANCES

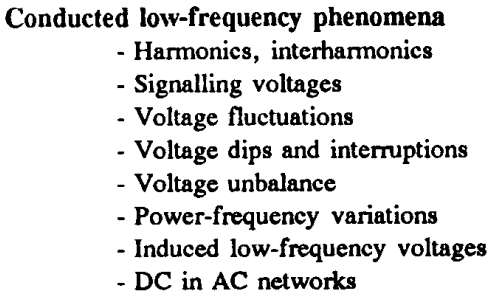

Radiated low-frequency phenomena

- Magnetic fields

- Electric fields

Conducted high-frequency phenomena

- Induced CW voltages or currents

- Unidirectional transients

- Oscillatory transients

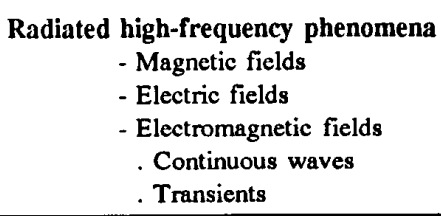

\begin{tabular}{l} 
Electrostatic discharge \\
Nuclear electromagnetic pulse \\
\hline \hline
\end{tabular}

Source: IEC 77(Secretariat)108 [7] 
A useful development in designing for electromagnetic compatibility is the recognition that equipment can be described in terms of several generic ports (Figure 1) representing the path of entry or emission of electromagnetic disturbances [8]. By breaking down the complex coupling of the equipment to its environment, addressing compatibility issues becomes more manageable. However, one should not make the error of presuming that these ports have no interaction, inside or outside the equipment.

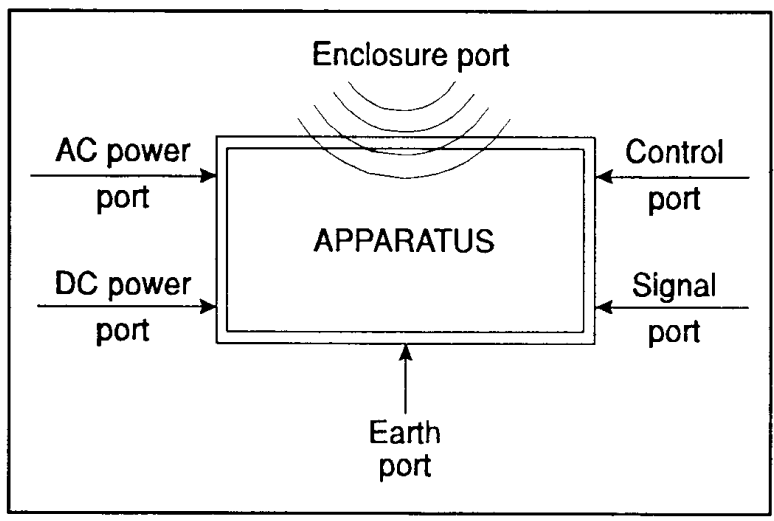

Source: Adapted from CENELEC prEN 50 082-2 [8]

Figure 1

Six ports of electronic equipment for entry or emission of electromagnetic disturbances

\section{Load Equipment Characteristics}

An essential element of electromagnetic compatibility is the characterization of load equipment - both its immunity levels and its emission levels. The basic concept of compatibility, expressed in the IEC definition, is that equipment should have a high probability "to function satisfactorily in its electromagnetic environment without introducing intolerable disturbances to anything in that environment." [7].

While simple and easy to agree with in principle, this concept is difficult to apply when the immunity and emission characteristics of the load equipment are not available to the system designer. This unavailability is results from either insufficient recognition of the issue or reluctance by some OEMs to publish data that might be misconstrued as a competitive weakness of their product. Actually, the weakness in the overall situation is the lack of understanding and cooperation among the three partners. Until such time as the usual process of voluntary standards (typically in North America) or the government-issued Directives (typically in Europe) impose full disclosure of the immunity and emission characteristics of the equipment, it will not be possible to design a system for predictable and reliable powersystem compatibility.

\section{System Compatibility Performance Criteria}

To remedy at least in part this undefined situation, System Compatibility (SC) performance criteria have been developed by the Power Electronics Applications Center (PEAC). This development is in response to the growing need for ensuring equipment compatibility at the interface between the utility and the end-user loads [9]. Load equipment OEMs generally do not have a sufficient knowledge base or the incentives to allocate their limited resources to research all aspects of utility compatibility for equipment that may be installed by third parties. Individual users may not have the appreciation of potential problems and the leverage necessary to bring about changes in equipment design. Last but not least, Architectural and Engineering firms (A\&E), while understanding the potential incompatibilities, may lack incentives or leverage to obtain redesign of load equipment or reconfiguration of the power supply.

Therefore, the main purpose of these SC criteria is to facilitate reconciliation of the inherent limitations of the power system environment with the characteristics of ever-changing electronic loads. The SC documents will provide a uniform approach to system compatibility until such time when the usual, slower standards development will have caught up with the fast-changing technology.

The System Compatibility approach is based on a three-step process:

1. Determine the electrical characteristics of the environment.

2. Determine the immunity and emission characteristics of candidate load equipment.

3. Identify the need, if any, of some interface between the environment and the equipment. 
For the purposes of the SC process, the characteristics of the environment can be obtained from environment description documents such as [5], [6] or [7]. In the absence of sufficient documentation, the immunity, emission, or mitigation characteristics need to be determined by tests. To be consistent and fair, the tests must be conducted according to a well-defined protocol, hence this development of SC performance criteria. The tests can then demonstrate that specific equipment is capable of operating in that environment, will not by itself degrade the environment, and involves a minimum of undesirable side effects.

These SC performance criteria tests are by necessity limited to the major aspects of compatibility and do not purport to replace more comprehensive tests performed by other parties, for instance those required for design engineering, regulatory compliance, or customer acceptance. The SC criteria have been developed from the point of view of electric utilities in consultation with other interested parties, including OEMs and end-users.

\section{THE SC DOCUMENT FAMILY}

The SC performance criteria provide a timely step in the application of power electronics equipment through objective testing for equipment of interest to electric utilities. For instance, some utilities are offering a comprehensive surge protection system to their customers, or are promoting energy savings through the use of electronic ballasts. To ensure success of such offerings, the utilities need to assess the performance of candidate devices offered by several OEMs. The test results are presented within a context of broad compatibility, not as a pass-fail judgment; expectations and results are presented to the sponsoring utility for analysis and final decision.

By making these criteria available to industry, it is expected that more consistent methods for evaluating power-system compatibility will be achieved. Reaching this goal will be facilitated by the gathering of application experience in the fast-evolving field of power electronics. This experience will then provide the basis for the usual standards development. The ultimate result will be more reliable and more cost-effective application of power-electronics equipment in an environment which is continuously evolving.
At the present time, several SC documents have been completed or are near completion; it is envisioned that the concept could be expanded to many more types of equipment. Table II shows the list of the major categories of documents under consideration, each to be subdivided into specific devices. For instance, the Power Conditioning Equipment category would include photovoltaic equipment, surge-protective devices, uninterruptible power supplies, etc. Among those, the rationale for documents in progress is briefly described in the following paragraphs.

TABLE II

SYSTEM COMPATIBILITY DOCUMENTS UNDER CONSIDERATION

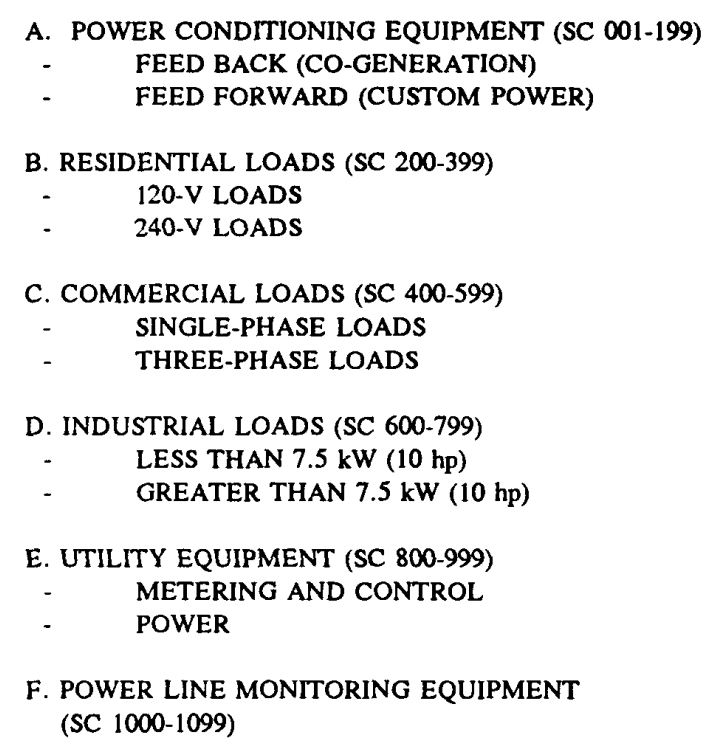

\section{SC-110 - Surge-Protective Devices Used in Low-Voltage AC Power Systems}

Surge-protective devices are applied in increasing numbers by end-users and now by some utilities on the meter side of their secondary systems. The surge current-handling capability of these devices ranges from $0.5 \mathrm{kA}$ to $10 \mathrm{kA}$, with a large number of suppliers offering these devices for installation at the service entrance or at receptacles within a building. Many OEMs also include these devices in the power port of their products. Some utilities now offer to their customers installing surge-protective devices with a guaran- 
teed protection. In such schemes, a high-energy arrester is installed at the service entrance, combined with protective devices connected next to the sensitive appliance [10].

The voluntary standards development process has not kept pace with the rapid development and application of these devices, in particular the coordination of two devices installed within a short distance of each other by uninformed end-users [11]. (Utilities offering the combined protection are in a better position to obtain coordination among the devices which they install, but still have no control over devices installed within the premises by the occupant [12].)

Another aspect that has not been comprehensively addressed is the failure mode of these devices; many test standards generally aim at demonstrating a specific rating, with only a pass/fail criterion, and the procedure does not go into failure mode determination. In contrast, SC-110 includes a test procedure to determine failure modes.

SC-120 - Reference Equalizers Surge-Protective Devices for Power and Communications Systems

The increasing use of equipment that includes a power port and a communications port, as defined in Figure 1, (cable TV receivers, smart telephones, Fax machines, desk-top publishing systems, distributed computer systems, industrial process control systems, etc.) has created a new problem in surge protection. Appropriate surge-protective devices correctly but independently applied to the two ports might not provide adequate protection against the problem of differences in the voltages appearing at the two ports during operation of one protective device.

To remedy this situation, OEMs are offering a device that routes both the power and the data connections through a single enclosure where the protective devices for each port share the same ground reference. Initially dubbed 'local ground window' [13], a new generic name of 'Surge Reference Equalizer' is now proposed. The SC-120 document describes a test schedule that exercises the protective devices of both the power port and the communications port (telephone or cable TV), separately and in combination.
Another compatibility concern is raised by the increase in harmonic currents produced by the new generation of power electronics. Possible areas of concern include the overheating of transformers and neutral conductors, interference associated with spurious zero-crossings, errors in revenue meter accuracy, and improper power-system control. The following are examples of SC documents addressing these concerns through performance test criteria.

\section{SC-410-High-Frequency Fluorescent Ballasts Used in Indoor Lighting Systems}

The increasing emphasis on energy conservation and the development of electronic ballasts have led some electric utilities to offer incentives to their customers for using these ballasts. However, in the present state of the market and standards development, these ballasts can create compatibility problems for users as well as for utilities. Interest in this issue is keen among both parties, hence the development of the performance criteria document for this type of equipment.

\section{SC-610-Adjustable Speed Drives Used in Commercial and Industrial Facilities}

The accelerating trend in applying adjustable speed drive systems provides a classic example of the race between an emerging technology and the development of adequate compatibility. These devices produce current harmonics (the emission aspect of EMC) and many are very susceptible to power line disturbances (the immunity aspect of EMC). At this stage of the development and application of these drives, it appears that more effort is needed in addressing their electromagnetic (power system) compatibility.

\section{SC-920 - Dry-Type Service Transformers Used in Commercial and Industrial Facilities ( $k$ Factor Rating)}

Here again, concerns about harmonic current effects have led to new approaches in rating transformers exposed to these currents, by applying a derating factor (' $k$ Factor') reflecting the harmonic loading. These concepts have not been fully explored and consensus on their general applicability has not yet been reached. 
Therefore, the 'living document' nature of the SC criteria lends itself well to addressing the compatibility and performance aspects of this type of new, changing equipment. In such rapidly moving technologies, the development of a corresponding SC document can address the need for interim data. Availability of these documents will then give breathing and reflection time for the development of appropriate standards and a full consideration of the EMC issues.

\section{CONCLUSIONS}

1. The development of System Compatibility Performance Criteria was undertaken as a contribution toward better operational compatibility at the interface between end-users and electric utilities.

2. These documents neither have nor seek the status of standards, but they offer a shared medium to the three-partner community of end-users, utilities, and original equipment manufacturers. This sharing of needs and experience will improve the applications of load equipment, in particular power electronics, until such time as voluntary or regulatory standards can be fully developed.

3. To that end, all three partners are invited to join in improving the family of System Compatibility documents - a growing set of living documents, not definitive standards - by review and constructive comments addressed to the author of this paper.

\section{REFERENCES}

[1] Martzloff, F.D., and Mendes, A., "Standards: Transnational aspects," Proceedings, First International Conference on Power Quality: End-Use Applications and Perspectives, Gif-sur-Yvette, France, 15-18 October 1991, pp. 31-34.

[2] IEEE Draft P519, 1991 - Recommended Practice for Harmonic Control.

[3] IEC Std 555-2 - Disturbances caused by equipment connected to the public low-voltage supply system, 1990.

[4] ANSI C84.1-1989 - American National Standard for Electric Power Systems and Equipment Voltage Ratings.

[5] ANSI/IEEE C62.41-1991 - Recommended Practice on Surge Voltages in Low-Voltage AC Power Systems.

[6] IEEE Draft P1250 - Guide on Service to Equipment Sensitive to Momentary Voltage Disturbances.

[7] Draft Intemational Standard 77(Secretariat) 108: Classification of Electromagnetic Environments, August 1991.

[8] CENELEC prEN 50 082-2, Draft 1991 - Generic Immunity Standard.

[9] Key, T.S. and Sitzlar, H.E., "Utility compatibility performance criteria for end-use equipment," Proceedings, Open Forum on Surge Protection Application, NISTIR 4657, National Institute of Standards and Technology, 1991, pp. 93-96.

[10] Maher, A.M., "Residential transient voltage surge suppression program, Proceedings, First International Conference on Power Quality: End-Use Applications and Perspectives, Gif-sur-Yvette, France, 15-18 October 1991, pp. 72-78.

[11] Lai, J.S. and Martzloff, F.D., "Coordinating cascaded surgeprotective devices," Proceedings, IEEE/LAS Annual Meeting, October 1991, pp. 1812-1819.

[12] Martzloff, F.D. and Leedy, T. E, "Selecting varistor clamping voltage: Lower is not better!" Proceedings, Zürich EMC Symposium, 1989, pp. 137-142.

[13] Martzloff, F.D., "Protecting computer systems against power transients," IEEE Spectrum, April 1990, pp. 37-40. 